\section{Leadership, Conflict, and Knowledge Sharing in the Public University}

José Luis Ballesteros-Rodríguez,

Nieves L. Díaz-Díaz, Inmaculada Aguiar-Díaz and Petra De Saá-Pérez

Departamento Economía Financiera y

Contabilidad, Universidad de Las Palmas de Gran

Canaria, Las Palmas de Gran Canaria, Spain

\section{Synonyms}

Disagreement and conflict at public universities; Leadership at public universities; Public universities knowledge management

\section{Definitions}

Task-oriented leadership refers to those leader behaviors that facilitate the understanding of task requirements, operating procedures, and the acquisition of task information. Relationshiporiented leadership refers to those behaviors regarding concern and respect for followers, looking out for their welfare. Task conflict is a perception of disagreement that involves differences in viewpoints, ideas, and opinions about the task being performed. Relationship conflict is a perception of interpersonal incompatibility among individuals, related to disagreements about values and personal issues. Knowledge sharing refers to deliberate interpersonal interaction processes, such as discussions, exchanging ideas, or joint problem-solving, where knowledge is exchanged.

\section{Introduction}

Knowledge management practices within public universities are becoming an important issue because they can help to increase universities productivity, in particular, scientific production. However, research carried out at public universities largely depends on effective collaboration for knowledge sharing among academics. In this regard, the success processes related to the Nonaka's SECI model of knowledge occur at the research group level, because researchers must know and trust each other to exchange their knowledge (Nistor et al. 2015).

In academic institutions, researchers obtain much of their knowledge through interactive face-to-face communications, rather than from written documents (Tan 2016). Thus, knowledge sharing among researcher could lead to better performance. However, people may have reasons for not making their knowledge available to others, treating their knowledge as a valuable and sensitive asset that must be carefully handled (He et al. 2014). For this reason, it is critical to understand the underlying effects of the collaboration among researchers and their willingness to 
share knowledge with others. In this sense, knowledge sharing can be fostered if leaders show certain behaviors related to knowledge management activities, convincing their group members that the exchange of ideas is beneficial for everyone (Tian et al. 2009). Besides, leaders can also help by reducing hoarding behavior, which generates high levels of conflict and trying to inspire group members to share knowledge (Bai et al. 2016).

\section{The Influence of Leadership on Knowledge Sharing}

In the university context, research is motivated by the individual objectives of academics, who may choose whether or not to share knowledge, but also with whom. For that reason, the knowledgesharing process becomes challenging and cannot be arbitrary manage (He et al. 2014). In this way, it is necessary to emphasize the role of university laboratories' leaders, who should promote a culture that fosters knowledge sharing, by convincing their group members that an open debate could be beneficial in terms of publications and citations (Tian et al. 2009). Leaders can help to eliminate hoarding behavior and try to inspire group members to share. Thus, knowledge sharing can be fostered if leaders have certain behaviors directly related to knowledge management activities. Examples of these behaviors could be: monitoring the environment for relevant new knowledge to share it within the group, challenging group members to try new approaches to problems, and pairing experienced individuals with less experienced members (Lee et al. 2010).

From a behavioral perspective, leadership styles can be divided into two categories: taskor relationship-oriented. A task-oriented leader deals with task accomplishment and facilitates the understanding of task requirements, operating procedures, and the acquisition of task information. A relationship-oriented leader facilitates behavioral interactions, cognitive structures, and attitudes that must be developed before members can work effectively as a team. This kind of leader shows concern and respect for his/her followers, looks out for their welfare, and expresses appreciation and support (Bass 1990).

\section{The Influence of Conflict Types on Knowledge Sharing}

In universities, academics collect and offer knowledge at different times and in different contexts. Sharing knowledge means that researchers have to invest time and effort in encouraging the flow of knowledge among their group members, who have different types of specialized expertise. This process enhances group conflict when members discuss their different points of view using arguments and counterarguments (Jiang et al. 2016). In this sense, task conflict is a perception of disagreement among group members about the content of their decisions, and it involves differences in viewpoints, ideas, and opinions about the task being performed. Relationship conflict is a perception of interpersonal incompatibility among individuals, related to disagreements about values and personal issues (Jehn et al. 2008). Both types of conflict can be seen in group members' moods, which may be expressed as negativity, irritability, and resentment on a personal level. However, although conflict has generally been viewed as unfavorable, a particular type of conflict could be beneficial because, in certain circumstances, task conflict can increase effectiveness. Groups that experience task conflict tend to make better decisions because this conflict encourages greater cognitive understanding of the issue being considered and the acceptance of group decisions, and it prevents groupthink. However, if the level of task conflict becomes so intense that information processing is blocked, this positive effect is reduced. Thus, if task conflict is not well managed, it can also be destructive to knowledge sharing (Bai et al. 2016; Jiang et al. 2016).

Although it is clear that knowledge-sharing processes have a cognitive nature, it must also be recognized that they have an essential relationship component. For knowledge sharing to exist, there must be emotional ties linking the group members because a positive attitude towards knowledge 
sharing requires the presence of social relationships based on trust. Thus, relationship conflict can be an obstacle because it hinders open communication and fosters hostility and suspicion about others' ideas and arguments, drastically reducing the group's information processing ability (Lu et al. 2011.

\section{How Can Leadership Influence the Conflict to Encourage Knowledge Sharing?}

The research group's performance is closely related to the leader's behavior because some members may be linked to the research group for a relatively short time, focus mainly on scientific issues, and not have much of an opportunity to get to know each other (Nistor et al. 2015). In this context, conflict is inherent to the interactions that occur within a group. But this conflict does not appear spontaneously or unjustifiably, and the way the leader manages conflict will have a substantial impact on the group's performance.

Leaders must help members to minimize the likelihood of reaching dysfunctional conflicts, seeking the right group environment that can stimulate creative chaos. This aim can be achieved through different leadership styles or behaviors. Leaders with task-oriented behavior often serve as examples for team members, reducing the negative consequences of task conflict by focusing on goal achievement and establishing well-defined patterns of communication (Bai et al. 2016). Moreover, team members who perceive a greater task-oriented leadership style experience positive emotions toward their colleagues more frequently, thus reducing relationship conflict. By contrast, a leader's relationship-oriented behavior will help to maintain or control an appropriate level of conflict by establishing good interpersonal relationships within the team to prevent both task and relationship conflicts.

\section{Conclusion}

Knowledge sharing has become an element of interest for all kinds of organizations that try to build on knowledge to achieve a competitive advantage. This interest is even higher in public organizations such as universities because their purpose is the creation and transfer of knowledge to society. In this regard, leaders' behaviors (taskor relationship-oriented) is a critical issue to consider because they have a direct, positive, and significant effect on knowledge sharing, as well as an indirect impact by reducing the negative impact of high levels of task and relationship conflict. Therefore, leaders can play a pivotal role in knowledge-sharing activities within research groups in public universities because they can create an environment of positive interactions among group members in order to facilitate knowledge-sharing activities, which, in turn, contribute to the creation of new knowledge (Rotolo and Messeni-Petruzzelli 2013). Knowledge sharing can be encouraged by fostering social interactions and stimulating interpersonal relationships that minimize conflict and improve proper behaviors among group members (Bai et al. 2016).

\section{Lessons for Public University Managers}

In the public sector, and in particular in public universities, it is necessary to shed light on understanding the knowledge management process. Managers in private companies have different tools and mechanisms to promote knowledge management practices in their organizations that may not be available to those who have similar positions in public organizations. Thus, the proper management of knowledge sharing in research groups can benefit management processes in universities as knowledge creation and dissemination centers. It should be noted that knowledge sharing has positive connotations for academics, which tend to view it as a valuable and pleasant experience. In other words, researchers believe that engaging in knowledge-sharing activities can be advantageous because it also has intrinsic 
rewards. This enjoyment is closely linked to the researcher's mood, which can be significantly undermined by the existence of high levels of conflict within the group.

Public universities should create a proper context where individuals feel motivated to engage in sharing knowledge. People in charge of public universities should consider the need to improve the leadership skills of academic's leaders because these they can help to create better conditions for knowledge sharing among academics. Besides, it should be noted that, within the academic context, a person who is considered "an expert" could lead a research group without having the appropriate leadership expertise, skills, and knowledge. Therefore, public university decision-makers should actively improve the leadership skills of these academics. This recommendation is reinforced by the fact that the issues addressed in this entry affect issues that are not related to the recruitment, compensation, or career planning fields, which usually are beyond the reach of research group leaders in public universities. In this sense, this entry highlights the need to focus on the aspects of human resources management that could be within the sphere of influence of academic research group leaders. Thus, through an adequate training program, public universities could help research leaders to manage their human resources better and promote higher levels of knowledge sharing, without having to modify incentive and reward systems. In universities and other public organizations, training programs could improve group leaders' interpersonal skills, so that they can be in a better position to prevent unpleasant situations within the group that can hinder knowledge sharing. Also, the content of training programs could help leaders to directly impact knowledge sharing because it might help them to find a proper strategy to foster knowledge sharing. Training can help them to identify and assess knowledge-sharing barriers and opportunities and develop an appropriate way to cope with the former and achieve the latter. Training programs could also improve the necessary communication skills to better transmit the importance of knowledge-sharing activities for the benefit of the whole group.
In conclusion, knowledge management can significantly contribute to effectiveness in public organizations. In this regard, this entry broadens the literature on knowledge management in public universities by addressing how the leader's role directly influences knowledge sharing. It also extends the literature by showing how leaders of public organizations, such as universities, can indirectly contribute to knowledge sharing, by reducing the harmful effects of task and relationship conflicts. In this way, this entry provides managers of public universities with interesting notions about leadership roles they have to foster to take advantage of knowledge as a strategic resource.

\section{Cross-References}

\author{
- Knowledge Utilization in Organizations \\ Managing Conflict in Organizations \\ - Team Leadership
}

\section{References}

Bai Y, Lin L, Li PP (2016) How to enable employee creativity in a team context: a cross-level mediating process of transformational leadership. J Bus Res 69(9):3240-3250

Bass BJ (1990) From transactional to transformational leadership: learning to share the vision. Organ Dyn 18(3):19-31

He H, Baruch Y, Lin CP (2014) Modeling team knowledge sharing and team flexibility: the role of within-team competition. Hum Relat 67(8):947-978

Jehn KA, Greer L, Levine S, Szulanski G (2008) The effects of conflict types, dimensions, and emergent states on group outcomes. Group Decis Negot 17(6):465-495

Jiang X, Flores HR, Leelawong R, Manz CC (2016) The effect of team empowerment on team performance: a cross-cultural perspective on the mediating roles of knowledge sharing and intra-group conflict. Int J Confl Manag 27(1):62-87

Lee P, Gillespie N, Mann L, Wearing A (2010) Leadership and trust: their effect on knowledge sharing and team performance. Manag Learn 41(4):473-491

Lu L, Zhou F, Leung K (2011) Effects of task and relationship conflicts on individual work behaviors. Int J Confl Manag 22(2):131-150 
Nistor N, Daxecker I, Stanciu D, Diekamp O (2015) Sense of community in academic communities of practice: predictors and effects. High Educ 69(2):257-273

Rotolo D, Messeni-Petruzzelli A (2013) When does centrality matter? Scientific productivity and the moderating role of research specialization and crosscommunity ties. J Organ Behav 34(5):648-670
Tan CNL (2016) Enhancing knowledge sharing and research collaboration among academics: the role of knowledge management. High Educ 71(4):525-556

Tian J, Nakamori Y, Wierzbicki AP (2009) Knowledge management and knowledge creation in academia: a study based on surveys in a Japanese research university. J Knowl Manag 13(2):76-92 